\title{
EFFECT OF GEOMETRICAL IMPERFECTIONS ON THE RESPONSE OF DRY-JOINT MASONRY ARCHES TO SUPPORT SETTLEMENTS
}

\author{
CHIARA FERRERO ${ }^{1,2 *}$, MICHELA ROSSI ${ }^{1}$, PERE ROCA ${ }^{2}$ AND CHIARA \\ CALDERINI ${ }^{1}$ \\ ${ }^{1}$ Department of Civil, Chemical and Environmental Engineering \\ University of Genoa \\ Via Montallegro 1, 16154 Genoa, Italy \\ email: chiara.ferrero@edu.unige.it,michela.rossi@dicca.unige.it, chiara.calderini@unige.it \\ (* corresponding author) \\ ${ }^{2}$ Department of Civil and Environmental Engineering \\ Technical University of Catalonia (UPC-BarcelonaTech) \\ Jordi Girona 1-3, 08034 Barcelona, Spain \\ e-mail: pere.roca.fabregat@upc.edu
}

Keywords: Masonry arches, Experimental tests, FE micro-modelling, Support displacements, Collapse mechanisms, Geometrical imperfections.

\begin{abstract}
This paper aims to investigate the effects of geometrical imperfections on the response of a scaled dry-joint arch to the vertical displacement of one support. The arch behaviour was analysed in the large displacement regime using both physical and numerical modelling. The experimental tests were performed on 1:10 small-scale models made of bicomponent composite blocks with dry joints. In order to evaluate the geometrical accuracy of the blocks, two different sets of voussoirs were produced. The numerical simulations were carried out using a finite element (FE) micro-modelling approach, where the arch was modelled as an assembly of very stiff voussoirs connected by nonlinear interfaces. Particular attention was paid to the interface stiffness, which was set so as to tune the numerical model with the experimental evidence. Experimental and numerical results were then compared in terms of collapse mechanism, hinge configuration and ultimate displacement capacity. The imperfections of the physical models were found to significantly affect the arch response.
\end{abstract}

\section{INTRODUCTION}

The safety assessment of masonry arches is a crucial issue for the conservation of cultural heritage, as arches have been often used as structural elements in historic masonry constructions. Masonry arches are sensitive to any change in the external environment and thus crack when the abutments move. Support movements can be produced by a wide range of different causes, including differential settlements, subsidence, landslides, soil heterogeneity, instability of the supporting walls/pillars, construction defects and many others. Although small 
movements do not represent a threat to stability since they can be easily accommodated by arches through the opening of some cracks (idealized as hinges [1]), large movements involving progressive changes in the geometry may lead to serious damage and collapse.

Over the years, considerable research effort has been devoted to finding new methods and computational tools to investigate the response of masonry arches to large support displacements. Several analytical methodologies were developed to evaluate the collapse mechanisms and ultimate displacement capacity of masonry arches with different geometries subjected to spreading supports (e.g. [2-4]) or generic support displacements (e.g. [5-7]). In the framework of numerical methods, different computational approaches were proposed to investigate the response of arches and, more in general, masonry structures to support displacements, such as finite element (FE) modelling (e.g. [8-10]), discrete element (DE) modelling (e.g. [11]) and rigid block modelling (e.g. [12,13]), among others. Nevertheless, both analytical and numerical methods require to be validated against experimental tests to prove their capability of accurately simulate the collapse of masonry structures. For this reason, the analytical and numerical predictions were often validated by comparison with the results from small-seale model testing (for arches on moving supports, the reader is referred to [2,5-10]). Compared to full-scale models, small-scale models offer several advantages, such as short setup times, reduced cost, and possibility to repeat the experiments several times. Furthermore, as first demonstrated by Heyman [1], they are effective to predict the collapse of masonry structures, which depends mainly on geometry rather than material strength and thus can b studied independently used to investigate displacements, but also

In the case of arches and vaults on moving st numerical predictions or analytical and numerical models are generally able to capture accurately the collapse

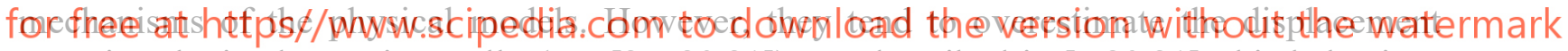
capacity obtained experimentally (see $[2,5,20,21]$ ). As described in $[5,20,21]$, this behaviour can be attributed to the imperfections and assembly inaccuracies that characterize the physical models compared to the "perfect" numerical ones. More in detail, the imperfections in the dimension of the individual blocks as well as the manual assembly of the physical models, which cannot be perfect, can lead to an inaccurate interlocking between the blocks. Furthermore, the edges of the blocks can become rounded if tests are repeated several times. The combination of these factors result in a reduction of the effective thickness of the physical models, causing collapse to occur for smaller ultimate displacements than the ones predicted by analytical or numerical simulations. A similar effect was also observed when testing smallscale arches under seismic actions. In this case, in order to take into account the imperfections of the physical models and tune the numerical results with the experimental evidence, several authors (e.g. [15-17,22]) proposed to consider a reduced thickness in the numerical models.

In this work, the effect of geometrical imperfections on the response of scaled dry-joint masonry arches to the settlement of one support was investigated through experimental tests and numerical simulations. The experimental tests were performed on 1:10 small-scale models built as dry-joint assemblages of bi-component composite voussoirs. Two sets of voussoirs with 
different geometrical accuracies were produced by using different manufacturing techniques. The numerical simulations of the experimental tests were carried out by adopting a FE micromodelling approach, according to which the arch was modelled as an assembly of very stiff voussoirs connected by no-tension friction interfaces. Differently from what proposed in the literature for small-scale arches subjected to seismic actions, the numerical results were here tuned with the experimental evidence by properly setting the stiffness of the interface elements. This approach was already adopted by the authors in [10] for the simulation of the experimental tests performed using one of the two sets of voussoirs.

The aims of this work were (i) to evaluate to what extent the imperfections of the physical models can affect the arch behaviour in terms of collapse mechanism, hinge position and displacement capacity, and (ii) to assess the capability of the proposed FE micro-modelling approach to simulate the experimental response.

\section{EXPERIMIENTAL TESTS}

The experimental tests were performed on a 1:10 small-scale model of a segmental dry-joint arch supported by two piers (Figure 1, Figure 2). The arch geometry was determined taking as a reference the cross-section of the barrel vaults that are generally used as ceiling in the main nave of historic masonry churches. More specifically, a two-course brick barrel vault with a radial thickness of $0.24 \mathrm{~m}$ and a net span of $6 \mathrm{~m}$ was considered. It is worth noting that, when

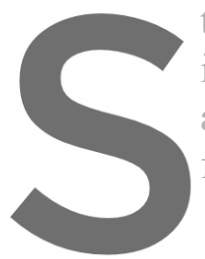
this type of vaults is include any backfill. abutments. For this reason, th from the horizontal plane.
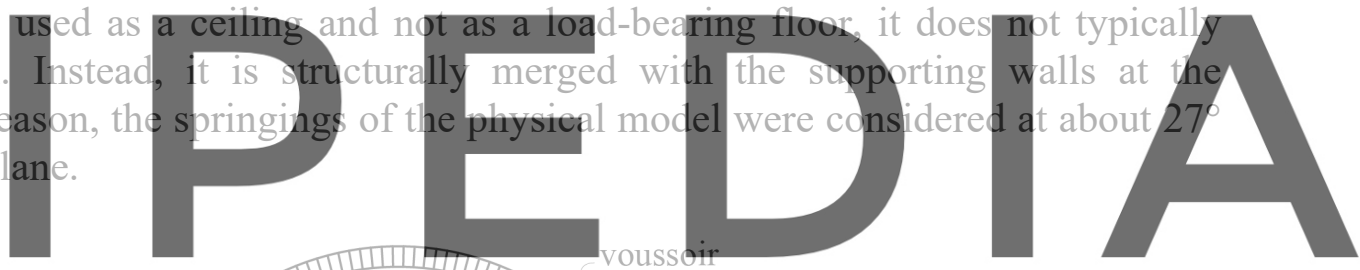

Register for free at https//www.seipedia.com to downlosd the veiesion without the watermark

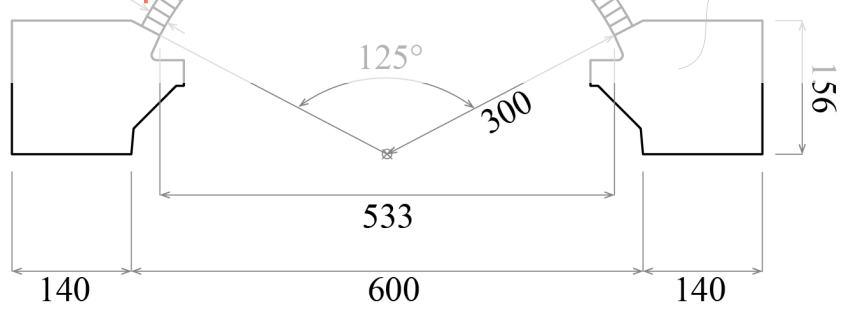

Figure 1: Geometry of the arch mock-up (in $\mathrm{mm}$ ).

Figure 1 shows the geometry of the mock-up. The arch has an angle of embrace of $125^{\circ}$, an internal radius of $300 \mathrm{~mm}$, a net span of $533 \mathrm{~mm}$, a radial thickness of $24 \mathrm{~mm}$ and a depth of $120 \mathrm{~mm}$. It is composed of 55 voussoirs with a height of $24 \mathrm{~mm}$ and a width of about $12 \mathrm{~mm}$. Each voussoir represents the scaled dimensions of two adjacent bricks of standard size $\left(60 \times 120 \times 240 \mathrm{~mm}^{3}\right)$ positioned with their longest side along the radial plane. The voussoirs are slightly trapezoidal in shape in order to compensate for the lack of mortar between them. The piers are shaped in such a way that they can sustain the plywood scaffolding needed to build 
the $\operatorname{arch}($ Figure 2a).

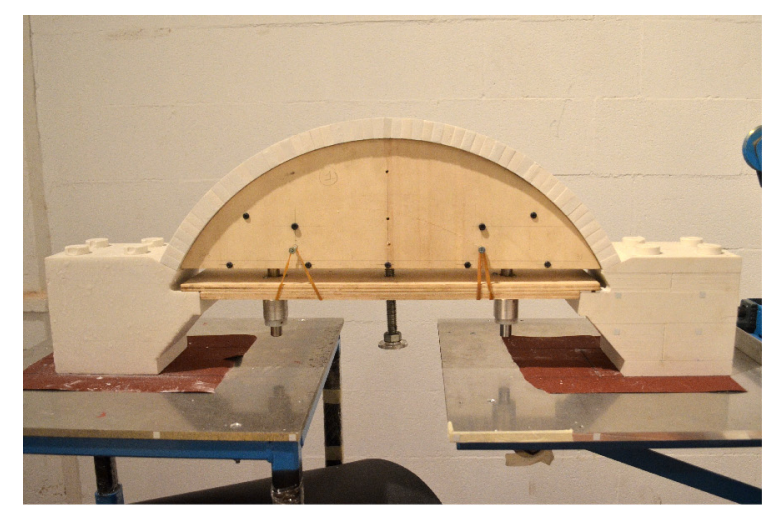

a)

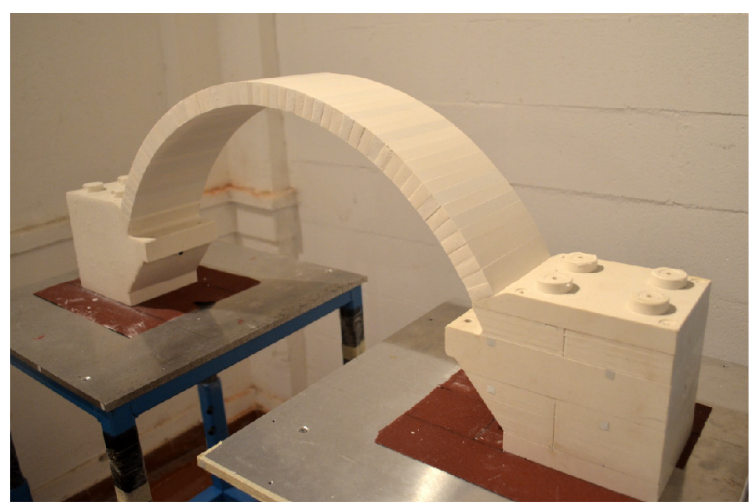

b)

Figure 2: Physical model: a) plywood scaffolding, b) view after the removal of the scaffolding.

All the blocks (voussoirs and piers) are made of a bi-component composite material, obtained by mixing a mineral powder with an acrylic polymer in aqueous solution. The mixture was poured, let it harden and then removed from special silicone moulds (Figure 3), which were created using aluminium matrices shaped as the blocks. The density of the blocks was measured to be $1.64 \mathrm{~g} / \mathrm{cm}^{3}$ and the friction angle $412^{\circ}$. The Young's modulus, determined by compressive tests (see [10]), was equal to $941 \mathrm{MPa}$.

Since this manufacturing technique is inno at testing, the dimensional accuracy of the block of voussoirs (Figure 3)
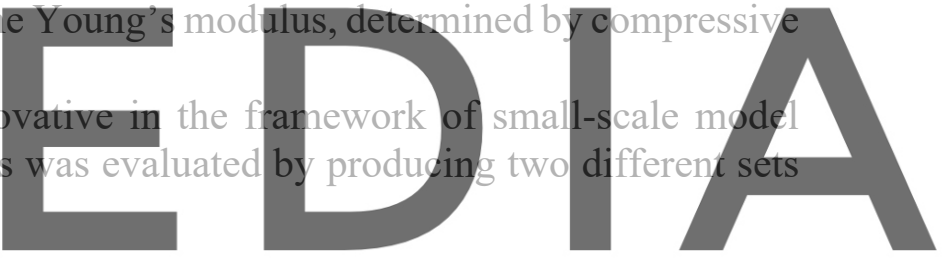

Register for free at https//www.scipedia.com to download the version without the watermark

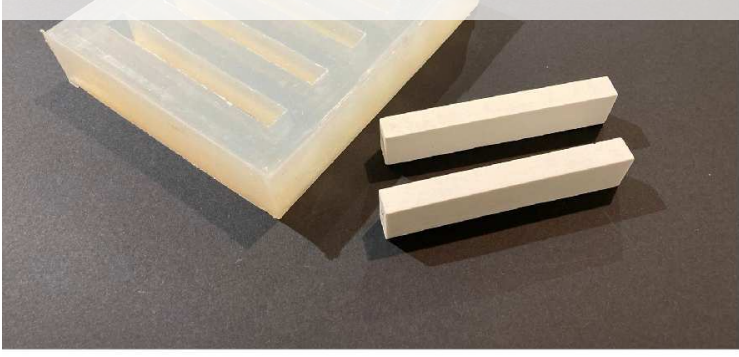

a)

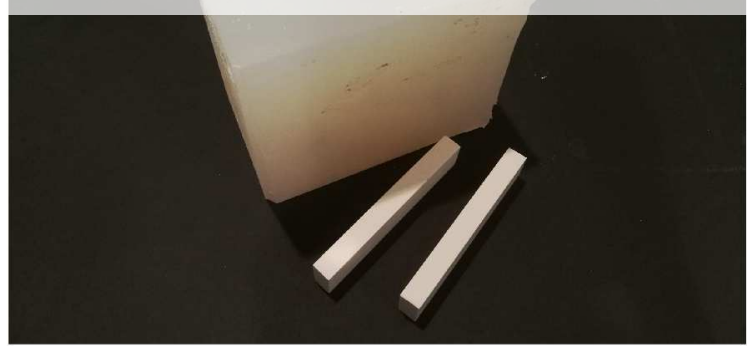

b)

Figure 3: Silicone moulds used to produce the voussoirs: a) $1^{\text {st }}$ set, b) $2^{\text {nd }}$ set.

For the $1^{\text {st }}$ set of voussoir, the aluminium matrices were manufactured using a manual milling machine; the mould was made of a deformable silicone and was created by positioning the aluminium matrices with their longest side horizontal (Figure 3a); the mixture was not vibrated; no admixtures were added to the bi-component composite material. For the $2^{\text {nd }}$ set of voussoirs, 
the aluminium matrices were produced through a CNC machine (precision $\pm 0.05 \mathrm{~mm}$ ); the mould was made of a stiffer silicone and was manufactured placing vertically the longest side of the aluminium matrices (Figure 3b); the mould was vibrated mechanically in order to eliminate the air bubbles from the freshly poured mixture; the mixture was fluidified by adding a plasticizer ( $1 \%$ of the total weight).

The two sets of voussoirs are significantly different. The voussoirs of the $1^{\text {st }}$ set (Figure $4 \mathrm{a}$ ) have more imperfections and less sharp corners compared to the voussoirs of the $2^{\text {nd }}$ set (Figure $4 b)$. Furthermore, when they are placed side by side, their lateral faces are not perfectly coplanar (Figure 4a). The use of a manual milling machine to produce the voussoirs of the $1^{\text {st }}$ set did not allow an accurate reproduction of the trapezoidal shape of the individual blocks. This resulted in a not perfect interlocking between voussoirs, causing gaps and hinges to occur (Figure 4c). Conversely, when a CNC machine was used to manufacture the blocks of the $2^{\text {nd }}$ set, the assembly was very accurate and no gaps between adjacent voussoirs were observed (Figure 4d).
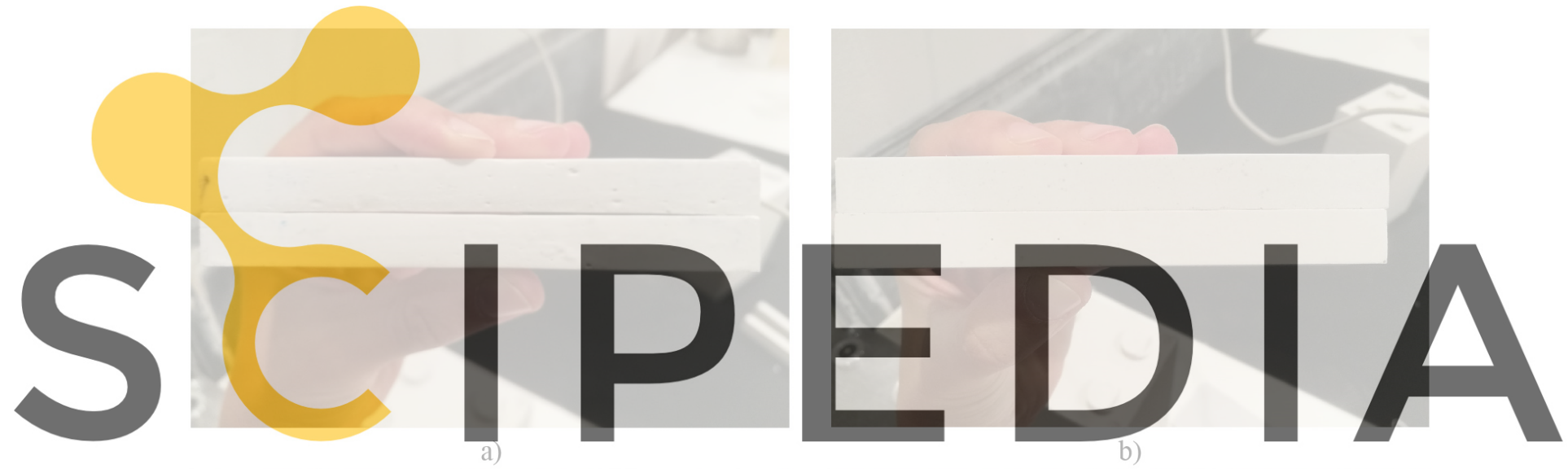

Register for free at https//www.scipedia.com to download the version without the watermark

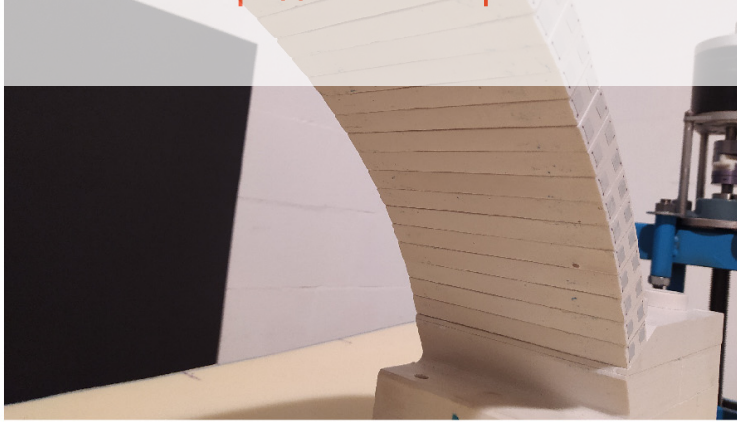

c)

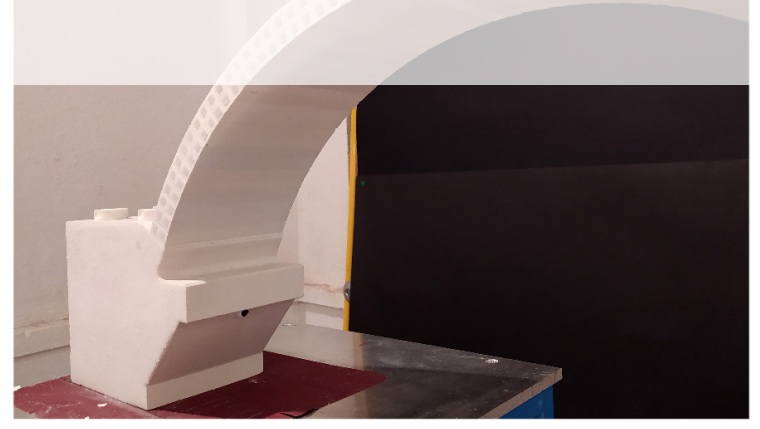

d)

Figure 4: Different sets of voussoirs produced: a-c) $1^{\text {st }}$ set, b-d) $2^{\text {nd }}$ set.

Figure 5 depicts the initial geometry of the physical models created using either set of voussoirs. The shape of the two models is slightly different since the keystone of the arch built with the $1^{\text {st }}$ set of voussoirs descended by few millimetres as soon as the scaffolding was removed (Figure 5a), while no significant movement was noticed for the arch built using the 
$2^{\text {nd }}$ set of voussoirs (Figure $5 \mathrm{~b}$ ). It is worth noting that the downward displacement of the keystone observed for $1^{\text {st }}$ set of voussoirs produced a slightly change in the geometry of the free-standing arch with respect to the "perfect" one shown in Figure 1.

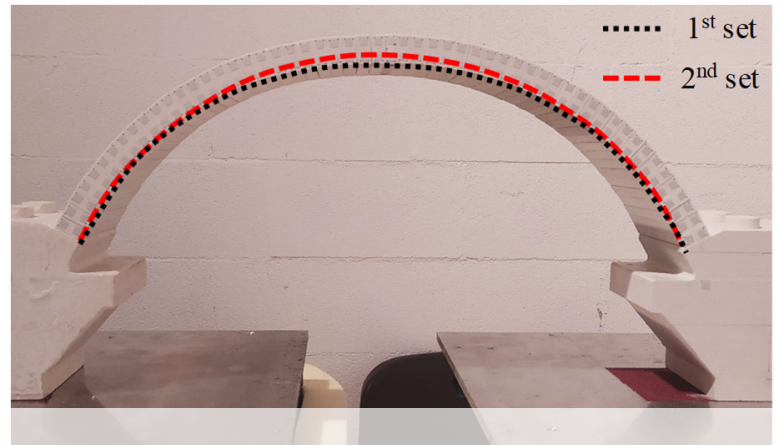

a)

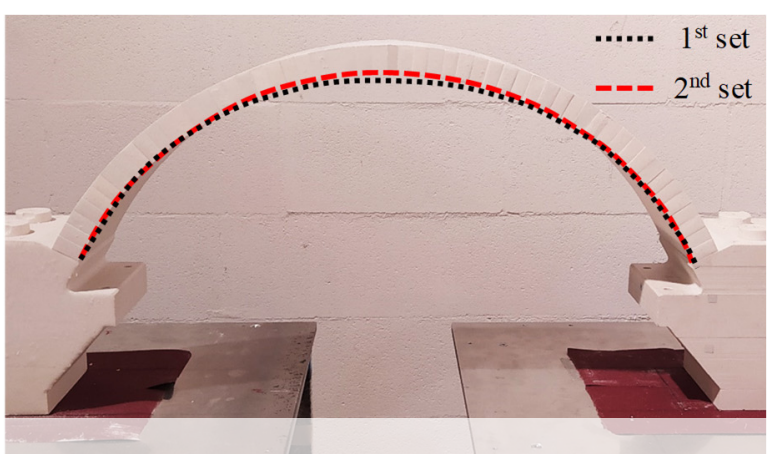

b)

Figure 5: Initial geometry of the arch after the removal of the scaffolding: a) $1^{\text {st }}$ set of voussoirs, b) $2^{\text {nd }}$ set of voussoirs

The arch was tested under an increasing downward quasi-static vertical displacement $\delta$ applied at the right support through an external stepper motor linear actuator controlled via software (Figure 6a). Fwo high-resolution, high
the development of the damage up to collapse
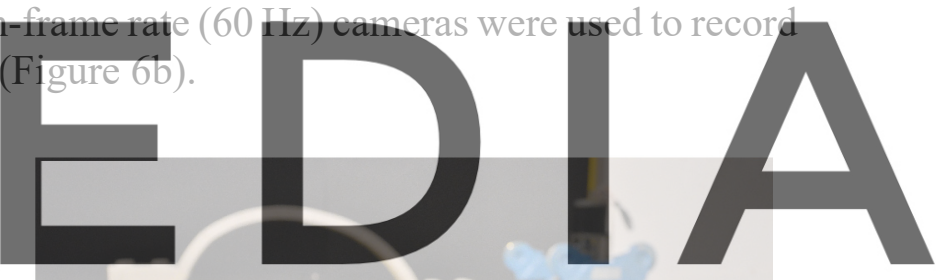

Register for free at https//www.scipedia.com to download the version without the watermark

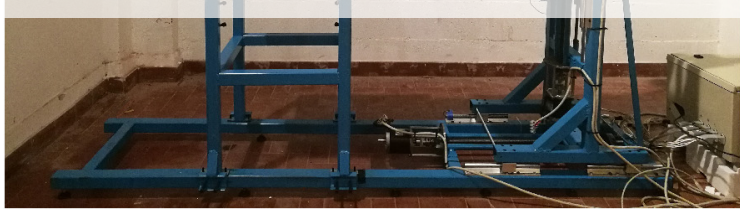

a)

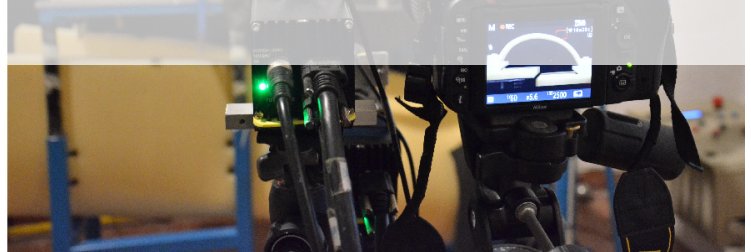

b)

Figure 6: a) Testing machine, b) high-resolution, high-frame rate cameras.

\section{FINITE ELEMENT MICRO-MODELLING}

The numerical simulations of the experimental tests were performed through the FEM software DIANA [23]. A two-dimensional FE model of the arch was created in Midas FX+ Version 3.3.0 (Customized Pre/Post-processor for DIANA software [24]) adopting a micromodelling approach, where each voussoir was modelled as a distinct (very stiff) block and dry joints were represented as no-tension frictional interfaces placed in between the voussoirs. 
Further interface elements were placed at the springing of the arch to allow for hinge opening at the supports. The piers were not included in the FE model, as they only provided support to the arch.

Four-node quadrilateral isoparametric plane stress elements (Q8MEM) were used to model the voussoirs, while 2D four-node line interface elements (L8IF) were employed for the interfaces. A mesh size of $2 \mathrm{~mm}$ (i.e. 12 FEs elements along the arch radial thickness) was adopted based on a sensitivity analysis on the ultimate vertical displacement $\delta_{u}$ obtained at collapse. For further details about the mesh sensitivity analysis, the reader is referred to [10].

The mesh of FE micro-model of the arch, composed of 5031 nodes and 4632 elements, is presented in Figure 7. Note that the outer edges of the interface elements placed at the supports were pinned to provide boundary conditions.

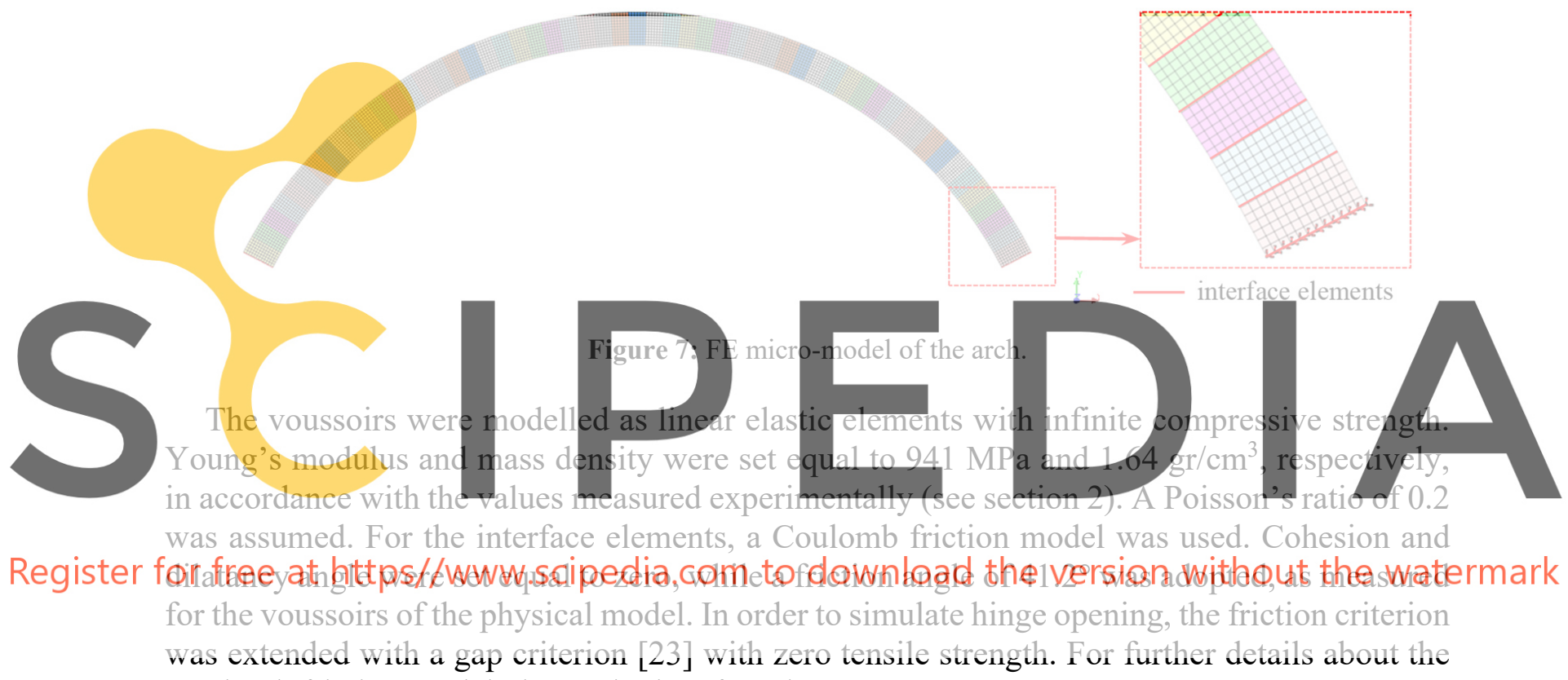

Coulomb friction model, the reader is referred to [23].

The stiffness of the interface elements was evaluated through a sensitivity analysis (Figure 8 ), where the collapse displacement $\delta_{u}$ was determined for different values of $k_{n}$ in the range $0.1 \div 100 \mathrm{~N} / \mathrm{mm}^{3}$ (this latter was defined according to the values proposed in [16]). The interface tangential stiffness $k_{s}$ was set equal to $0.5 k_{n}$ for any considered value of $k_{n}$. This choice was made only to optimize numerical convergence, since the ratio between the two stiffnesses did not influence the arch structural response. As described by the authors in [10], very large stiffness values simulate rigid contact surfaces, allowing to treat the arch as a rigid-no tension structure, but they lead to significantly overestimate the displacement capacity obtained from experimental methods. Conversely, reduced stiffness values enable to consider the imperfections (and resulting deformability) that characterize the contact surfaces of the physical models. With the aim of simulating the experimental tests, the interface normal stiffness was chosen so that the numerical collapse displacement matched closely the experimental result for 
each of the two sets of voussoirs considered. Consequently, $k_{n}$ was set equal to $0.25 \mathrm{~N} / \mathrm{mm}^{3}$ and $5.2 \mathrm{~N} / \mathrm{mm}^{3}$ for the $1^{\text {st }}$ and $2^{\text {nd }}$ sets of voussoirs, respectively.

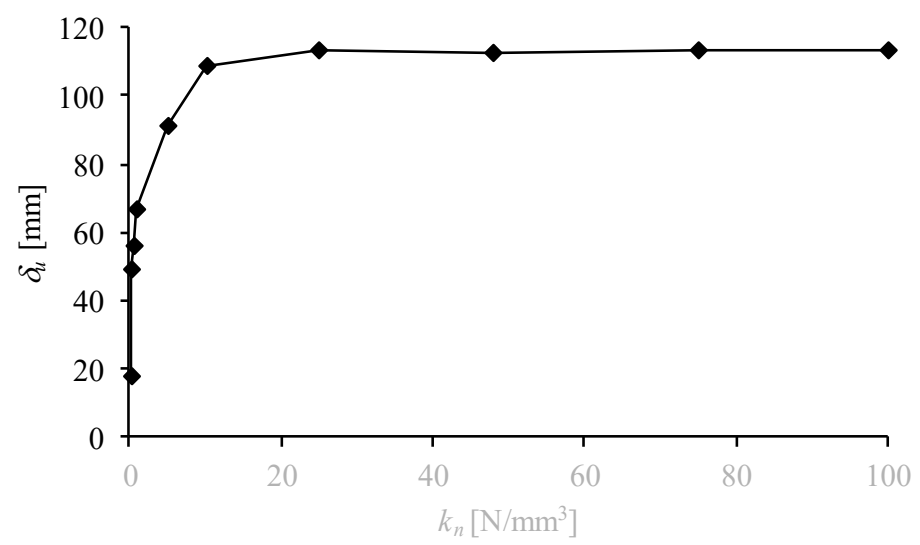

Figure 8: Collapse displacement $\delta_{u}$ vs. interface normal stiffness $k_{n}$.

The response of the arch to large support displacements was evaluated through non-linear static analyses. After the application of the self-weight, the imposed vertical displacement $\delta$ was increased monotonically until collapse was reached. A regular Newton-Raphson iteration method combined with criterion with a toleranc into account by adopting

\section{The}

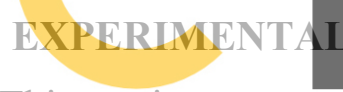

This section presents and compares the experimental and numerical results obtained from
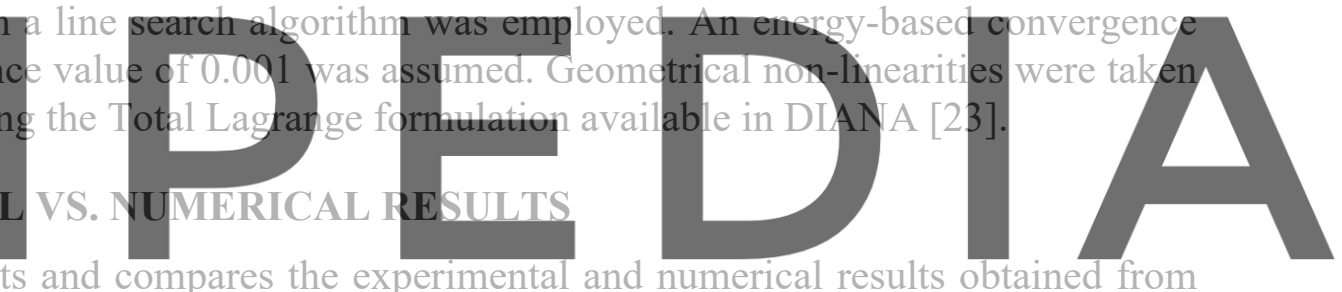

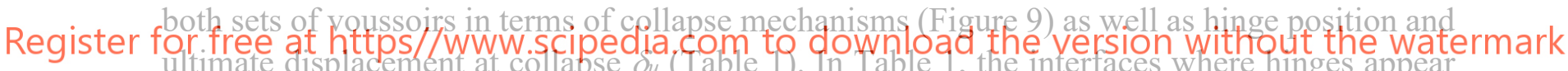
are numbered from left to right, being interface no. 1 the interface at the left support.

The collapse mechanisms obtained from the experimental test and relevant numerical simulation for the $1^{\text {st }}$ of voussoirs are illustrated in Figure 9a-c. In the experimental test (Figure 9a), three hinges, A, B and C, initially occurred in the sequence I-E-E (from left to right, where $\mathrm{E}=$ extrados; $\mathrm{I}=$ intrados). Hinge A was located at the haunches between $11^{\text {th }}$ and $12^{\text {th }}$ voussoirs (interface no. 12), hinge B appeared close to midspan between $31^{\text {st }}$ and $32^{\text {nd }}$ voussoirs (interface no. 32), and hinge $\mathrm{C}$ opened at the right support (interface no. 56). Hinges $\mathrm{B}$ and $\mathrm{C}$ remained in their initial position and did not move as the imposed vertical displacement increased. Conversely, hinge A moved towards the crown by one voussoir just before collapse. The arch collapsed by an asymmetrical four-hinge mechanism when a fourth hinge (D) occurred at the left support at the extrados for a vertical displacement of $48.9 \mathrm{~mm}$ (Figure 9a).

Figure $9 \mathrm{c}$ illustrates the collapse mechanism predicted by FE analyses when adopting a value of $k_{n}$ equal to $0.25 \mathrm{~N} / \mathrm{mm}^{3}$. For the latter, the numerical collapse displacement $\delta_{u}(48.8 \mathrm{~mm})$ matched very closely the experimental one. Collapse occurred again by an asymmetrical fourhinge mechanism with hinges located according to the sequence E-I-E-E. The predicted final 
hinge position agreed well with the experimental results since hinges $B, C$ and D appeared at the same location of the physical model, and hinge A was shifted by one voussoir only. Differently, hinge A did not move with increasing support displacements. Despite the good agreement in terms of displacement capacity and hinge position, the FE analysis did not perfectly capture the actual behaviour of the physical model, since hinges A and B, which concentrated in one single interface in the test, appeared to be distributed over adjacent interfaces in the numerical simulation. Nevertheless, this discrepancy could be attributed to the not perfect geometry of the physical model, which was slightly different from the numerical one since the keystone descended by few millimetres after the scaffolding was removed (as already shown in Figure 5).

Figure $9 \mathrm{~b}$ and Figure $9 \mathrm{~d}$ show the collapse mechanisms obtained for the $2^{\text {nd }}$ set of voussoirs from the experimental test and numerical simulation, respectively. In the test, the three initial hinges $\mathrm{A}, \mathrm{B}$ and $\mathrm{C}$ appeared in the sequence I-E-E and did not move as the support displacements increased. The position of hinges B and $\mathrm{C}$ was very similar to that obtained for the $1^{\text {st }}$ set, since hinge $\mathrm{C}$ occurred again at the left support and the location of hinge $\mathrm{B}$ differed by only one block, opening between $30^{\text {th }}$ and $31^{\text {st }}$ voussoirs (interface no. 31). However, a significant difference was found in the final position of hinge A, which appeared four blocks closer to the left support (interface no. 9) in the $2^{\text {nd }}$ set compared to the $1^{\text {st }}$ set. The failure mode was the same as that obtained for the $1^{\text {st }}$ set of voussoirs, since collapse occurred when the

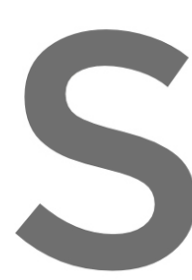
fourth hinge D appeared at the left support.

significantly larger, bein results obtained for $k_{\text {r }}$

the experimental results

latter, the predicted position of hinges $\mathrm{A}, \mathrm{C}$ and $\mathrm{D}$
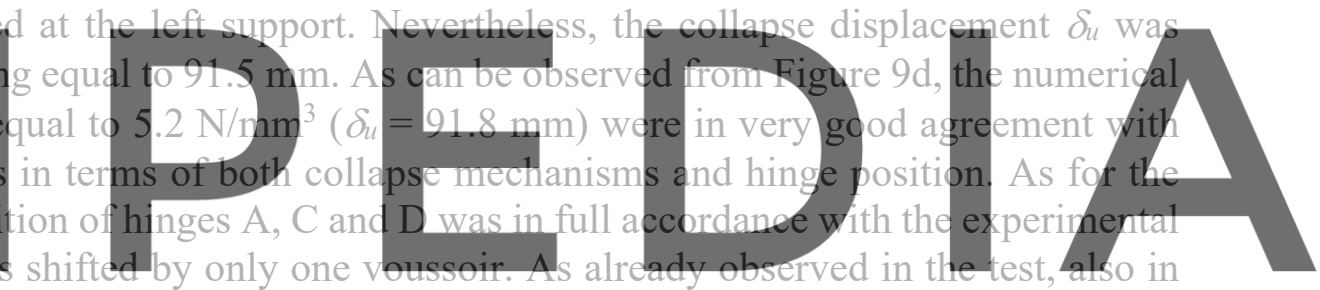

the numerical simulation all hinges remained in their initial position and did not move with

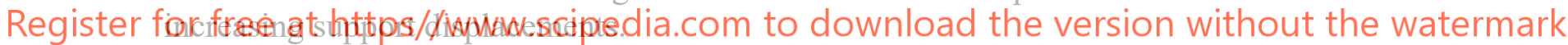

Table 1: Comparison of numerical and experimental results in terms of hinge position (indicated with the interface where hinges appear, numbered from left to right) and collapse displacement $\delta_{u}$.

\begin{tabular}{lcccc}
\hline & \multicolumn{2}{c}{$1^{\text {st }}$ set of voussoirs } & \multicolumn{2}{c}{$2^{\text {nd }}$ set of voussoirs } \\
\cline { 2 - 5 } & Experimental & Numerical & Experimental & Numerical \\
\hline Position of hinge A at collapse & 13 & $11-12$ & 9 & 9 \\
Position of hinge B at collapse & 32 & $29-30-31-32$ & 31 & 30 \\
Position of hinge C at collapse & 56 & 56 & 56 & 56 \\
Collapse displacement $\delta_{u}[\mathrm{~mm}]$ & 48.9 & 48.8 & 91.5 & 91.8 \\
\hline
\end{tabular}




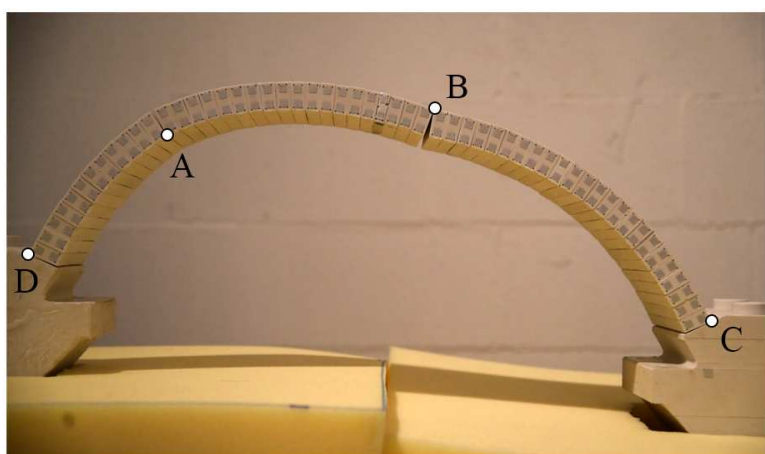

a)

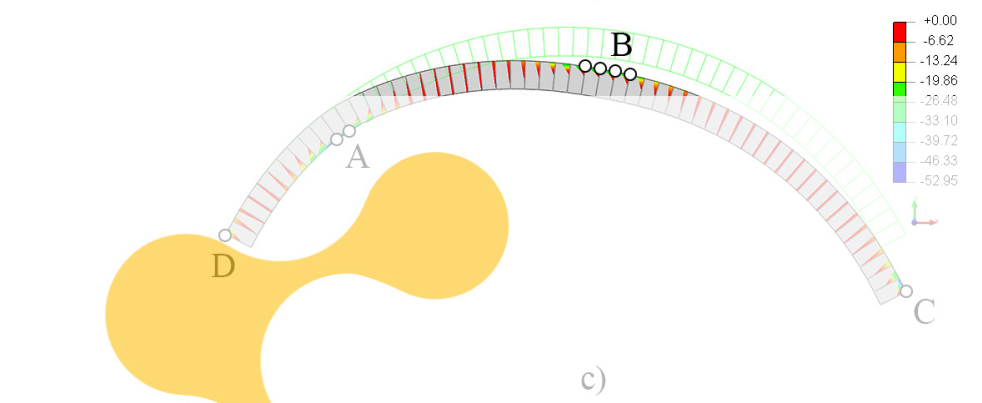

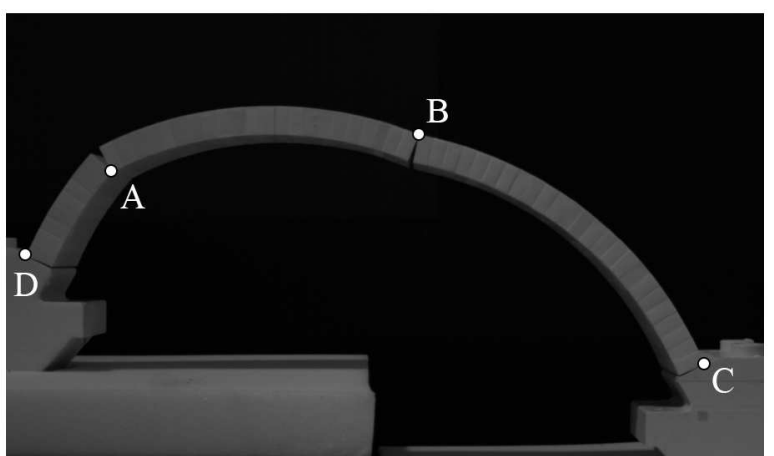

b)

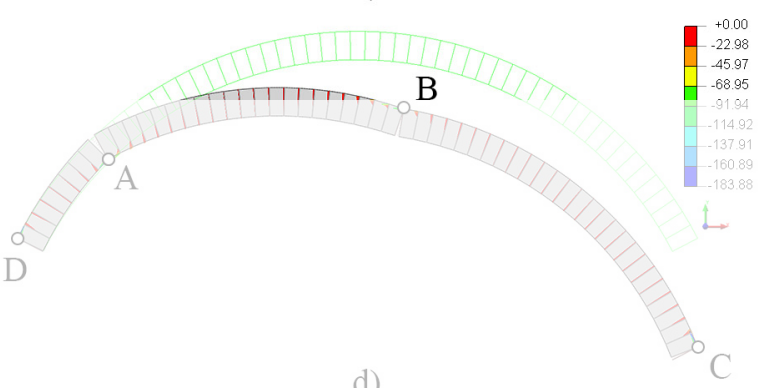

d)
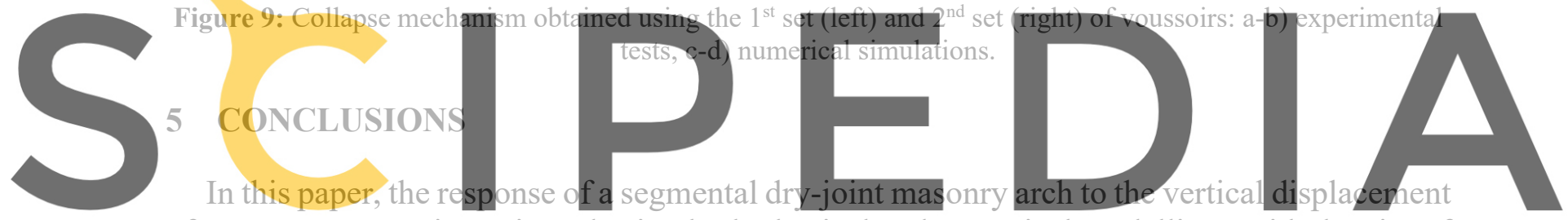

of one support was investigated using both physical and numerical modelling. With the aim of

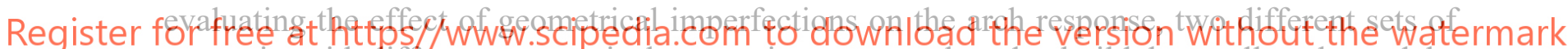
voussoirs with different geometrical accuracies were employed to build the small-scale models.

The experimental tests were then simulated through FE micro-modelling. The stiffness of the interface elements used to model the dry joints was calibrated so that the ultimate displacement capacity obtained numerically matched closely the experimental one.

The results of the experimental tests proved that the imperfections and assembly inaccuracies of the physical models significantly affect the arch response, especially in terms of displacement capacity. Indeed, although the same collapse mechanism occurred for either set of voussoirs, the collapse displacement obtained using the $1^{\text {st }}$ set, which was characterized by more imperfections, was significantly lower than that obtained with the $2^{\text {nd }}$ set.

For both sets of voussoirs, the numerical predictions were in good agreement with the experimental results in terms of collapse mechanism, hinge position and displacement capacity. This demonstrated that calibrating the interface stiffness based on the experimental evidence is an effective strategy to accurately capture the experimental response of dry-joint masonry arches to large support displacements. The difference in the hinge distribution obtained when simulating the test performed using the $1^{\text {st }}$ set of voussoirs can be explained considering that the geometry of the physical model was slightly different from the perfect numerical one. 
In conclusion, this work provides a contribution for a better understanding of the effect of geometrical imperfections on the response of scaled dry-joint masonry arches. Future works will include the application of different configurations of support displacements as well as the measurement of the reactions at the arch supports in the experimental tests. This will allow to evaluate the effect of geometrical imperfections on the arch response in terms of support reaction-displacement curves.

Acknowledgements. The financial support of PRIN 2015 Program by the Italian Ministry of Education, University and Research (MIUR) is gratefully acknowledged for funding the research project "Protecting the Cultural Heritage from water-soil interaction related threats" (Prot. No. 2015EAM9S5), which is the main framework of the study presented in this article.

\section{REFERENCES}

[1] Heyman, J. The stone skeleton. Structural engineering of masonry architecture. Cambridge University Press, Cambridge (1995).

[2] Ochsendorf, J. A. The masonry arch on spreading supports. Struct. Eng. (2006) 84(2):2935.

[3] Coccia, S., Di Carlo, F. and Rinaldi, Z. Collapse displacements for a mechanism of spreading-induced supports in a masonry arch. Int. J. Adv. Struct. Eng. (2015) 7(3):307320.

[4] Di Carlo, F. and Coccia, S. Collapse state of elliptical masonry arches after finite displacements of the supports. Eng. Fail. Anal. (2020) 114.

[5] Galassi, S., Misseri, G., Rovero, L. and Tempesta, G. Failure modes prediction of masonry voussoir arches on moving supports. Eng. Struct. (2018) 173:706-717.

[6] Zampieri, P., Simoncello, N. and Pellegrino, C. Structural behaviour of masonry arch with no-horizontal springing settlement. Frat. ed Integrità Strutt. (2018) 12(43):182-190.

[7] Smars, P. Kinematic Stability of Masonry Arches. Adv. Mater. Res. (2010) 133-134:429434.

[8] Alforno, M., Monaco, A., Venuti, F. and Calderini, C. Validation of Simplified Micromodels for the Static Analysis of Masonry Arches and Vaults, Int. J. Archit. Herit. (2020).

[9] Masciotta, M-G., Pellegrini, D., Girardi, M., Padovani, C., Barontini, A, Lourenço, PB, Brigante, D. and Fabbrocino, G. Dynamic characterization of progressively damaged segmental masonry arches with one settled support: experimental and numerical. Frat. ed Integrità Strutt. (2020) 51:423-441.

[10] Ferrero, C., Rossi, M., Roca, P. and Calderini, C. Experimental and numerical analysis of a scaled dry-joint arch on moving supports. Int. J. Mason. Res. Innov. (2020).

[11] McInerney, J. and DeJong, M. J. Discrete Element Modeling of Groin Vault Displacement Capacity. Int. J. Archit. Herit. (2015) 9(8):1037-1049.

[12] Gilbert, M. and Melbourne, C. Rigid-block analysis of masonry structures. Struct. Eng. (1994) 72(21).

[13] Portioli, F. and Cascini, L. Large displacement analysis of dry-jointed masonry structures subjected to settlements using rigid block modelling. Eng. Struct. (2017) 148:485-496. 
[14] Calderini, C., Lagomarsino, S., Rossi, M., De Canio, G., Mongelli, M.L. and Roselli, I. Shaking table tests of an arch-pillars system and design of strengthening by the use of tierods. Bull. Earthq. Eng (2015) 13(1):279-297.

[15] DeJong, M., De Lorenzis L., Adams, S. and Ochsendorf J.A. Rocking stability of masonry arches in seismic regions. Earthq. Spectra (2008) 2:847-865.

[16] Gaetani, A., Lourenço P. B., Monti, G. and Moroni, M. Shaking table tests and numerical analyses on a scaled dry-joint arch undergoing windowed sine pulses. Bull. Earthq. Eng. (2017) 15:4939-4961.

[17] Misseri, G., DeJong, M.J. and Rovero, L. Experimental and numerical investigation of the collapse of pointed masonry arches under quasi-static horizontal loading. Eng. Struct. (2018) 173:180-190.

[18] Shapiro E.E. Collapse mechanism of small-scale unreinforced masonry vaults. M.S. thesis in Building Technology, Massachusetts Institute of Technology (2012).

[19] Pippard A.J.S. and Ashby, R. An experimental study of the voussoir arch. J. Inst. Civ. Eng Journal of the Institution of Civil Engineers (1939) 10(3):383-404.

[20] Van Mele, T., McInerney, J., DeJong, M. and Block P. Physical and Computational Discrete Modelling of Masonry Vault Collapse,' In: Proceedings of 8th International Conference on Structural Analysis of Historical Constructions, (2012), pp. 2552-2560.

[21] Quinonez, A., Zessin, J., Nutzel, A. and Ochsendorf J.A. Small-Scale Models for Testing Masonry Structures. Adv. Mater. Res. (2010) 133-134:497-502.

[22] Albuerne, A, Williams, M and Lawson V. Prediction of the failure mechanism of arches under base motion using DEM based on the NSCD method. Wiadomości Konserw (2013) 34:41-47.

[23] TNO DIANA BV. DIANA Finite Element Analysis User's Manual Release 9.6, Delft, The Netherlands (2014).

[24] Midas FX+ for DIANA, Customized Pre/Post-processor for DIANA (2013). 